\title{
Prevalence and Factors of Burnout among Healthcare Workers in Eastern Province, Saudi Arabia
}

\author{
Khayriyah Rasool Al Owa1, Andrea Valentine'2, Adetunji Bakare³, Idowu Y. Akanmu, \\ Adeniyi Adeboye ${ }^{1}$
}

${ }^{1}$ University of Hail College of Public Health and Health Informatics, Hail, KSA

${ }^{2}$ UKCBC/Bath Spa University Programme, London, UK

${ }^{3}$ University of Minnesota School of Public Health, Minneapolis, USA

${ }^{4}$ Brandeis University, Waltham, USA

Email: adeboye05@yahoo.co.uk

How to cite this paper: Al Owa, K. R. Valentine, A., Bakare, A., Akanmu, I. Y., \& Adeboye, A. (2021). Prevalence and Factors of Burnout among Healthcare Workers in Eastern Province, Saudi Arabia. Open Journal of Social Sciences, 9, 36-45.

https://doi.org/10.4236/jss.2021.910003

Received: May 5, 2021

Accepted: October 10, 2021

Published: October 13, 2021

Copyright $\odot 2021$ by author(s) and Scientific Research Publishing Inc. This work is licensed under the Creative Commons Attribution International License (CC BY 4.0).

http://creativecommons.org/licenses/by/4.0/

\begin{abstract}
Introduction: The word "Burnout" comes from the term "engine failure". In the 1970s Herbert Freudenberger introduced "burnout" to describe severe emotional stress of the general workforce. The symptoms of burnout could include fatigue, disappointment, anger, negligence, lack of motivation and a sense of ineffectiveness. Method: This study aimed to measure the prevalence of burnout among healthcare workers in the Eastern Province of Saudi Arabia and to determine the factors associated with burnout levels. To attain this, the Maslach Burnout Inventory (MBI) was used together with the demographic variables and factors of burnout of a pilot study of 16 participants. The MBI was distributed online and convenient sampling technique was used to measure burnout through three subscales: exhaustion, professional efficacy and cynicism. Results: 402 healthcare workers participated. Burnout shows high percentages in the three subscales: Exhaustion 269 (67\%), Professional Efficacy $61(15 \%)$ and Cynicism 241 (60\%). There is no strong relationship between the burnout and the characteristic of participants. The factors that show significant statistical difference are: gender, educational level, break time and work-life balance. However, the variables were not significant for all subscales. Conclusion: Several studies established strong links between work and burnout with additional factors linked to it. This study shows that there are high percentages of burnout among healthcare workers specifically within the three subscales. Although, most studies do not consider healthcare administrators, they were included here and they also showed high levels of burnout. The current COVID-19 pandemic also had an impact on the result of this study.
\end{abstract}




\section{Keywords}

Satisfaction, Workload, Fatigue, Health, Middle East

\section{Introduction}

Studies have shown that burnout negatively impacts job performance, job satisfaction and interpersonal relationships (Chemali et al., 2019; Aldrees et al., 2013). In the 1970s Herbert Freudenberger introduced burnout to describe severe emotional stress of the general workforce (Aldrees et al., 2013). Burnout is a syndrome with three main dimensional underlying symptoms; emotional exhaustion (EX), cynicism (CY), and personal Efficacy (PE) in which an affected individual develops a feeling of failure (Aldrees et al., 2013; Al Sareai et al., 2013). Burnout is characterized by many other symptoms including fatigue, disappointment, anger, negligence, lack of motivation and sense of ineffectiveness (Chemali et al., 2019). Burnout is highly prevalent among healthcare professionals due to their work environment, low social support and emotional distress (Chemali et al., 2019; Hameed et al., 2018).

A universal questionnaire called Maslach Burnout Inventory (MBI) has been used in many previous and extant studies to explore the burnout phenomenon and to determine its associated factors (Aldrees et al., 2013; Al Sareai et al., 2013). For example, a study conducted in Thailand by Wisetborisut and colleagues (2014) among healthcare workers revealed that burnout has a significant effect on them, due to working different and sometimes long shifts. This was even more common among those who had less than 8 hours to rest between shifts (Wisetborisut et al., 2014). Health professionals, specifically physicians and nurses working in the critical care area were documented to have high rate of burnout due to working long hours in a high stress environment (Le Gall et al., 2011; Shahriari et al., 2014). Residents were also considered in a study to be more at risk of burnout compared to specialists or consultants; or another factor, the age of workers, where those who are older have less chance to experience burnout at work (Aldrees et al., 2013; Al Sareai et al., 2013). However, it is proven that residents or even undergraduate students have high rates of burnout, which shows us that the healthcare workers, especially those working long hours and having unusual shift patterns almost always experience burnout at some point during their career (Hameed et al., 2018; Aldubai et al., 2019).

Moreover, Middle East studies show high percentages of prevalence of burnout among healthcare providers $(40 \%-60 \%)$ and show high levels of burnout especially among nurses (Chemali et al., 2019). In Arab countries, there is an estimation that burnout is moderate to high among healthcare providers (Elbarazi et al., 2017). Furthermore, a study conducted to include the healthcare workers in both Saudi Arabia and the United Arab Emirates shows high level of burnout among all healthcare providers (Al-Omari et al., 2019). 
While other studies have explored the prevalence of burnout and determined the factors that may potentiate it among medical professionals (Chemali et al., 2019; Aldrees et al., 2013), there is dearth of research exploring its prevalence among health care workers in Saudi Arabia. The aim of this research was to measure the prevalence of burnout among healthcare workers in the Eastern Province of Saudi Arabia to assess how it has impacted them during the COVID-19 pandemic. We investigated the prevalence of burnout and determined the associated factors potentiating the occurrence of burnout among workers in healthcare sector in the Eastern Province of Saudi Arabia.

\section{Method}

Based on the statistical yearbook for Saudi Arabia 2018, the total number of healthcare workers in Eastern Province (excluding Al Hasa and Hafr Al Batin as both have separate statistics) is 24,321 . We calculated the sample size using confidence level of $95 \%$ and confidence interval of 5 . The sample size with enough power required to determine significant association is 378 .

Data were collected using online survey of MBI general survey using convenient sampling technique. A pilot study of 16 participants was performed to test the reliability and validity of the questionnaire and result showed a Cronbach's Alpha on standardized items as .874. Through the online survey, we received 441 answered questionnaires with signed consent forms. We applied exclusions and inclusion criteria of the study and found detected eligible participants.

A total of 441 questionnaires were received through an online survey. The net total after excluding participants who are not matching the inclusion criteria was 402. Using SPSS, the answers were coded in the program and the results illustrated as shown in various tables below.

Data were collected and analysed using Statistical Package for Social Sciences (SPSS) program version 21. It produced results using descriptive statistical measurements for the demographic information and the scales questions result in description. Ordinal logistic regression was used to find out the associated factors and cross tab for the distribution of results of burnout among the values of factors.

Approval from the institutional research review board of the University of Hail was sought and received and all research activities were carried out according to the guidelines of the scientific research review board.

\section{Results}

The prevalence of burnout among workers in healthcare sector in Eastern Province of Saudi Arabia based on the three subscales of MBI survey is showing in Table 1 high percentages in exhaustion (EX) (67\%) and cynicism (CY) (60\%) respectively. Unlike the previous two scales, professional efficacy (PE) is interpreted in the opposite direction as its statement in the survey has the reverse direction in which the interpretation of high score means the low burnout and low score means high burnout. The prevalence of PE burnout is $15 \%$ and it shows high percentage of feeling good about their accomplishments and efficacy in the 
work with $61 \%$ (see Figure 1).

Moreover, high score of burnouts was stratified over the characteristics of participants. The age group classified according to the World Health Organization (WHO) classification of ages and it shows that the young age group from 25 to 44 years have the most participation (87\%) of the total sample and the high percentages of burnout among the three subscale EX (89\%), PE (92\%) and CY (90\%). Moving to gender variable, females formulate $77 \%$ and have high percentages through the three subscales also EX (84\%), PE (43\%) and CY (78\%). Most participants were Saudis (97\%) and this is reflected on the results. The marital status variable is showing participation from single $(23 \%)$ and married (75\%) employees where the higher burnout was scored for married people. Furthermore, the educational levels have different participation in which the bachelor's degree is the most participated category (76\%) with high scores in the subscales of burnout. Although the survey targeted all healthcare workers, there was low response from doctors (16\%), pharmacists (19\%) and administrators (11\%). While most responses were for nurses (29\%) and other healthcare professionals of the allied services (40\%) it shows near the same percentages of burnout for both categories. However, the survey also includes other factors to measure the prevalence of burnout including years of experience, break time, shift work and work-life balance. The break times clearly shows high percentages of burnout score for those who didn't have regular break time (see Table 2).

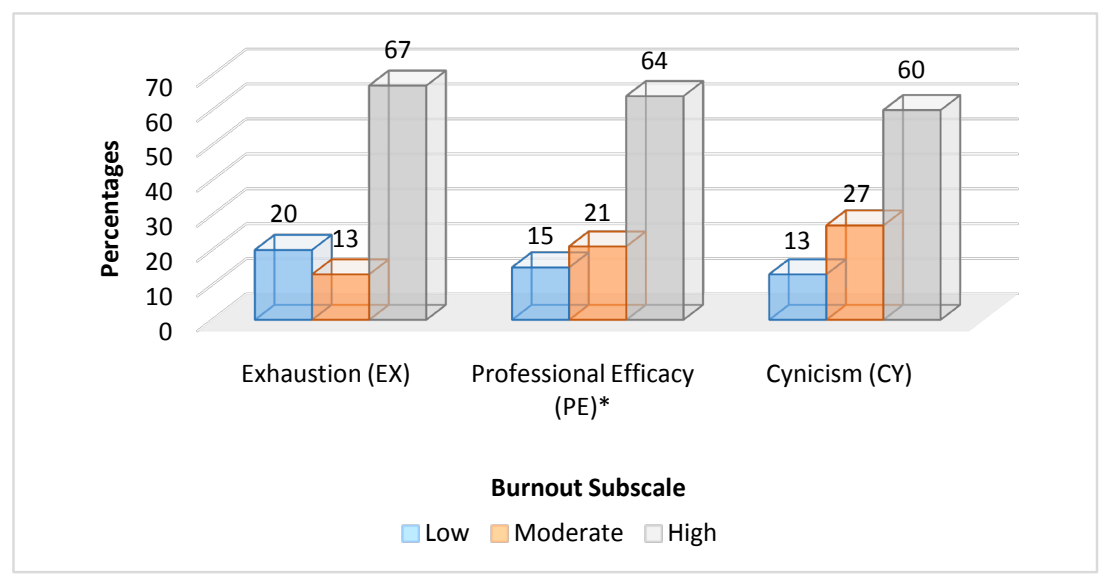

Figure 1. Prevalence of burnout among workers in healthcare sector in Eastern Province, Saudi Arabia based on burnout subscales. ${ }^{\star}$ Professional Efficacy interpreted in the opposite direction from EX and CY.

Table 1. Prevalence of burnout among workers in healthcare sector in Eastern Province, Saudi Arabia based on burnout subscales.

\begin{tabular}{cccc}
\hline Subscale & $\begin{array}{c}\text { Low } \\
\text { n (\%) }\end{array}$ & $\begin{array}{c}\text { Moderate } \\
\text { n (\%) }\end{array}$ & $\begin{array}{c}\text { High } \\
\text { n (\%) }\end{array}$ \\
\hline Exhaustion (EX) & $80(20 \%)$ & $53(13 \%)$ & $269(67 \%)$ \\
Professional Efficacy* (PE) & $61(15 \%)$ & $84(21 \%)$ & $257(64 \%)$ \\
Cynicism (CY) & $52(13 \%)$ & $109(27 \%)$ & $241(60 \%)$ \\
\hline
\end{tabular}

*Professional Efficacy interpreted in the opposite direction from EX and CY. 
Table 2. Characteristics of participants stratified by burnout subscales high score.

\begin{tabular}{|c|c|c|c|c|}
\hline Characteristics & Frequency (\%) & $\begin{array}{c}\text { Exhaustion scored high } \\
\text { burnout } n=269 \\
n(\%)\end{array}$ & $\begin{array}{c}\text { Professional Efficacy scored } \\
\text { high burnout } n=61 \\
n(\%)^{*}\end{array}$ & $\begin{array}{l}\text { Cynicism scored high } \\
\text { burnout } n=241 \\
n(\%)\end{array}$ \\
\hline \multicolumn{5}{|l|}{ Age } \\
\hline 24 years old and below & $17(4 \%)$ & $9(3 \%)$ & $1(2 \%)$ & $9(4 \%)$ \\
\hline 25 to 44 years old & $348(87 \%)$ & $239(89 \%)$ & $56(92 \%)$ & $218(90 \%)$ \\
\hline 45 to 64 years old & $37(9 \%)$ & $21(8 \%)$ & $4(7 \%)$ & $14(6 \%)$ \\
\hline \multicolumn{5}{|l|}{ Gender } \\
\hline Male & $92(23 \%)$ & $42(16 \%)$ & $18(30 \%)$ & $52(22 \%)$ \\
\hline Female & $310(77 \%)$ & $227(84 \%)$ & $43(70 \%)$ & $189(78 \%)$ \\
\hline \multicolumn{5}{|l|}{ Nationality } \\
\hline Saudi & $390(97 \%)$ & $261(97 \%)$ & $60(98 \%)$ & $236(98 \%)$ \\
\hline Non-Saudi & $12(3 \%)$ & $8(3 \%)$ & $1(2 \%)$ & $5(2 \%)$ \\
\hline \multicolumn{5}{|l|}{ Marital Status } \\
\hline Single & $92(23 \%)$ & $56(21 \%)$ & $10(16 \%)$ & $56(23 \%)$ \\
\hline Married & $301(75 \%)$ & $207(77 \%)$ & $51(84 \%)$ & $180(75 \%)$ \\
\hline Divorced & $8(2 \%)$ & $6(2 \%)$ & $0(0 \%)$ & $5(2 \%)$ \\
\hline Widow & $0(.2 \%)$ & $0(0 \%)$ & $0(0 \%)$ & $0(0 \%)$ \\
\hline \multicolumn{5}{|l|}{ Educational Level } \\
\hline Secondary school & $4(1 \%)$ & $1(.4 \%)$ & $0(0 \%)$ & $2(.8 \%)$ \\
\hline Diploma & $74(18 \%)$ & $53(20 \%)$ & $10(16 \%)$ & $38(16 \%)$ \\
\hline Bachelor & $271(67 \%)$ & $185(69 \%)$ & $37(61 \%)$ & $169(70 \%)$ \\
\hline Higher educations & $53(13 \%)$ & $30(11 \%)$ & $14(23 \%)$ & $32(13 \%)$ \\
\hline \multicolumn{5}{|l|}{ Income Level } \\
\hline Less than $10,000 \mathrm{SR}$ & $104(26 \%)$ & $73(27 \%)$ & $12(20 \%)$ & $69(29 \%)$ \\
\hline 10,000 to 39,999 SR & $288(72 \%)$ & $188(70 \%)$ & $49(20 \%)$ & $167(69 \%)$ \\
\hline 40,000 to 50,000 SR & $6(2 \%)$ & $4(1 \%)$ & $0(0 \%)$ & $3(1.2 \%)$ \\
\hline More than 50,000 SR & $4(1 \%)$ & $4(1 \%)$ & $0(0 \%)$ & $2(.8 \%)$ \\
\hline \multicolumn{5}{|l|}{ Specialty } \\
\hline Doctor & $63(16 \%)$ & $39(14 \%)$ & $11(18 \%)$ & $38(16 \%)$ \\
\hline Nurse & $115(29 \%)$ & $92(34 \%)$ & $14(23 \%)$ & $70(29 \%)$ \\
\hline Pharmacist & $19(5 \%)$ & $14(5 \%)$ & $1(2 \%)$ & $14(6 \%)$ \\
\hline Other allied services & $162(40 \%)$ & $96(36 \%)$ & $29(48 \%)$ & $91(38 \%)$ \\
\hline Administrative & $43(11 \%)$ & $28(10 \%)$ & $6(10 \%)$ & $28(12 \%)$ \\
\hline \multicolumn{5}{|l|}{ Years of Experience } \\
\hline 5 years or less & $152(38 \%)$ & $98(36 \%)$ & $26(43 \%)$ & $101(42 \%)$ \\
\hline 6 to 10 years & $84(21 \%)$ & $61(23 \%)$ & $8(13 \%)$ & $51(21 \%)$ \\
\hline 11 to 15 years & $93(23 \%)$ & $62(23 \%)$ & $19(31 \%)$ & $59(24 \%)$ \\
\hline More than 15 years & $73(18 \%)$ & $48(18 \%)$ & $8(13 \%)$ & $30(12 \%)$ \\
\hline \multicolumn{5}{|l|}{ Break Time } \\
\hline Constant & $116(29 \%)$ & $64(24 \%)$ & $21(34 \%)$ & $55(23 \%)$ \\
\hline Not constant & $286(71 \%)$ & $205(76 \%)$ & $40(66 \%)$ & $186(77 \%)$ \\
\hline \multicolumn{5}{|l|}{ Shift Work } \\
\hline Yes & $170(42 \%)$ & $112(42 \%)$ & $23(38 \%)$ & $106(44 \%)$ \\
\hline No & $232(58 \%)$ & $157(58 \%)$ & $38(62 \%)$ & $135(56 \%)$ \\
\hline \multicolumn{5}{|l|}{ Off Days } \\
\hline Below 8 days & $167(42 \%)$ & $116(43 \%)$ & $22(36 \%)$ & $107(44 \%)$ \\
\hline 8 days and above & $235(59 \%)$ & $153(57 \%)$ & $39(64 \%)$ & $134(56 \%)$ \\
\hline \multicolumn{5}{|l|}{ Working Hours } \\
\hline 9 hours or less & $294(73 \%)$ & $186(69 \%)$ & $45(74 \%)$ & $169(70 \%)$ \\
\hline More than 9 hours & $108(27 \%)$ & $83(31 \%)$ & $16(26 \%)$ & $72(30 \%)$ \\
\hline
\end{tabular}

${ }^{*}$ Professional Efficacy interpreted in the opposite direction from EX and CY. 
Despite the high percentages of burnout among the three subscales, there is no clear or strong relationship between the different variables with the burnout result (see Table 3). Ordinal logistic regression was used to find out the statistical significance variables for p-value less than .05 and confidence interval of $95 \%$. However, EX shows, there are significant statistical differences for gender $p$ $=.000$ toward female. Furthermore, break time is a significant factor with $p$ $=.007 \mathrm{in}$ as a reverse relation for those with no regular break time that have higher chances of burnout. Moreover, working hours show $p=.019$, which tells us that employees with 9 or more working hours (daily) show high percentages of EX burnout. Gender has the same impact on PE subscale with $p=.017$. Also, the educational level has the same value $p=.017$ with gender. It shows that workers with high educational level have high percentages of burnout for the PE and they may feel a sense of ineffectiveness. On the other hand, the last subscale, CY shows significance with break time $p=.000$ and working hours $p=.040$ the same issues of relation direction.

\section{Discussion}

The prevalence of burnout among healthcare workers in Eastern Province of Saudi Arabia shows high percentages for the three subscales of MBI general survey, EX (67\%), PE (15\%) and CY (60\%). Our findings suggest that the risk of burnout related to exhaustion was associated with gender, whether or not staff took regular breaks and length of working hours, while the risk of burnout related to cynicism was associated with whether or not staff took regular breaks and length of working hours. Also, the risk of burn out (low PE) was associated with gender and educational level.

Table 3. Ordinal logistic regression of burnout factors.

\begin{tabular}{cccc}
\hline Characteristics & $\begin{array}{c}\text { Exhaustion } \\
\boldsymbol{P} \text {-Value }\end{array}$ & $\begin{array}{c}\text { Professional Efficacy } \\
\boldsymbol{P} \text {-Value }\end{array}$ & $\begin{array}{c}\text { Cynicism } \\
\boldsymbol{P} \text {-Value }\end{array}$ \\
\hline Age & .258 & .824 & .140 \\
Gender & .000 & .017 & .885 \\
Nationality & .954 & .409 & .696 \\
Marital Status & .090 & .337 & .241 \\
Educational Level & .159 & .017 & .432 \\
Income Level & .586 & .891 & .216 \\
Specialty & .442 & .788 & .685 \\
Years of Experience & .595 & .069 & .134 \\
Break Time & .007 & .982 & .000 \\
Shift Work & .315 & .795 & .181 \\
Off Days & .900 & .070 & .912 \\
Working Hours & .019 & .116 & .040 \\
\hline
\end{tabular}


Our findings highlight that female healthcare workers (HCWs) have a higher risk of EX and PE related burnout than male workers, and that HCWs who do not have regular break time and those who work for 9 or more hours have a higher risk of exhaustion and Cynicism related burnout. Likewise, HCWs with a higher educational level have a higher risk of burnout related to sense of ineffectiveness.

Women in healthcare experience a higher burnout than their male counterparts because; they are responsible for the emotional needs of their families, combined with a number of other challenging roles they have (Lee et al., 2021). Burnout associated with long working hours may be due to a reduction in sleep time and increased susceptibility to job stress (Lin et al., 2021). It is well documented that periodic breaks facilitate short-term productivity and lessen exhaustion and uneasiness, consequently HCWs who do not have regular break time may be less productive and may experience more exhaustion and physical discomfort resulting in burnout (Monaghan et al., 2017).

Comparing the results with studies applied in Saudi Arabia, this study found high prevalence of burnout among healthcare workers (Aldrees et al., 2013; Al Sareai et al., 2013). In comparison with some of the burnout measures that applied using the students survey in other researches, we can notice that there is increase in the results for students or residents to be approximately near this study results (Hameed et al., 2018; Aldubai et al., 2019). Even though there is no statistical difference in the variables, this study found some other factors to be considered in the future analysis of burnout, such as working hours. On the other hand, a previous study conducted in Saudi Arabia found no direct correlation between working hours and the burnout levels of residents (Hameed et al., 2018). Moreover, gender is the most common variable to have the significant statistical difference with high score of burnouts (Altannir et al., 2019; Agha et al., 2015). Unlike the result in this study, some studies show a relation with other variables including the marital status as strong relationship (Al-Omari et al., 2019), and years of experience (Al-Omari et al., 2019; Wisetborisut et al., 2014). Educational level is found to be significant variable in other studies as well as this research to show that higher education levels lead to higher burnout levels (Wisetborisut et al., 2014). However, it is important to consider that this study was carried out during the Coronavirus pandemic. All healthcare workers have been under extreme pressure, which could have impacted on the results by showing higher levels of burnout than it would have done otherwise. Although a lot of studies have been conducted to measure burnout in the healthcare sector, but there has been no focus on healthcare administrators. This study included administrators, but their participation was low, 43 out of 402 . Furthermore, this small sample of the administrators shows high levels of burnout. The variables used in this research were collected from different studies to try to get a fuller picture. However, this study still found no clear indication about the most pertinent factors; and the MBI survey did not take the predictors of burnout into 
consideration. Another limitation of the tool is that burnout is a dynamic state, and the result of the MBI survey may have been different if it was conducted at a different time (Williamson et al., 2018).

\section{Conclusion and Recommendation}

Several studies conducted around the world including Saudi Arabia show that there is a clear link between work and burnout levels. This study shows high percentages of burnout among the three subscales of the general MBI survey for healthcare workers in the Eastern Province of Saudi Arabia. This study found that variables, such as gender, working hours, regular breaks and education levels, have significant impact on burnout levels. However, there is a need to further study the predictors and factors related to burnout to expatiate their relationship with increased burnout levels. Additionally, most researches do not consider healthcare administrators; however, this study found high burnout levels among healthcare administrators as well. Therefore, it would be beneficial to include this group in future researches on burnout levels among healthcare workers.

Upon noting the results of this study, it is recommended for hospital management boards to find and make provision for suitable and regular training programs to decrease employees' pressure at work. Regular supervisory visits of staff by the hospital human resource departments could help identify and support employees who are at high risk of burnout, as these sessions could enable management to recognize the signs of burnout and offer support for example through extra training and making work schedules flexible. Work rotation could be a solution for routine and repetitive work, as this could have a positive impact on employees' lack of motivation and sense of ineffectiveness. The human resource department should institute a mechanism for talent management of employees with extra capabilities to train them to perform better.

As this study was conducted during the Coronavirus pandemic, it is important to note that this may have had a negative effect on the results. Therefore, it is strongly recommended that the study is repeated at the end of the pandemic.

\section{Conflicts of Interest}

The authors declare no conflicts of interest regarding the publication of this paper.

\section{References}

Agha, A., Mordy, A., Anwar, E., Saleh, N., Rashid, I., \& Saeed, M. (2015). Burnout among Middle-Grade Doctors of Tertiary Care Hospital in Saudi Arabia. Work, 51, 839-847. https://doi.org/10.3233/WOR-141898

Al Sareai, N. S., Al Khaldi, Y. M., Mostafa, O. A., \& Abdel Fattah, M. M. (2013). Magnitude and Risk Factors for Burnout among Primary Health Care Physicians in Asir Province, Saudi Arabia. Eastern Mediterranean Health Journal, 19, 426-434.

https://doi.org/10.26719/2013.19.5.426 
Aldrees, T. M., Aleissa, S., Zamakhshary, M., Badri, M., \& Sadat-Ali, M. (2013). Physician Well-Being: Prevalence of Burnout and Associated Risk Factors in a Tertiary Hospital, Riyadh, Saudi Arabia. Annals of Saudi Medicine, 33, 451-456. https://doi.org/10.5144/0256-4947.2013.451

Aldubai, SamiA. R., Aljohani, A., Alghamdi, A., Alghamdi, K., Ganasegeran, K., \& Yenbaawi, A. (2019). Prevalence and Associated Factors of Burnout among Family Medicine Residents in Al Madina, Saudi Arabia. Journal of Family Medicine and Primary Care, 8, 657. https://doi.org/10.4103/jfmpc.jfmpc $268 \quad 18$

Al-Omari, A., Al Mutair, A., Shamsan, A., \& Al Mutairi, A. (2019). Predicting Burnout Factors among Healthcare Providers at Private Hospitals in Saudi Arabia and United Arab Emirates: A Cross-Sectional Study. Applied Sciences, 10, 157. https://doi.org/10.3390/app10010157

Altannir, Y., Alnajjar, W., Ahmad, S. O., Altannir, M., Yousuf, F., Obeidat, A., \& Al-Tannir, M. (2019). Assessment of Burnout in Medical Undergraduate Students in Riyadh, Saudi Arabia. BMC Medical Education, 19, 34. https://doi.org/10.1186/s12909-019-1468-3

Chemali, Z., Ezzeddine, F. L., Gelaye, B., Dossett, M. L., Salameh, J., Bizri, M., \& Fricchione, G. (2019). Burnout among Healthcare Providers in the Complex Environment of the Middle East: A Systematic Review. BMC Public Health, 19, Article No. 1337. https://doi.org/10.1186/s12889-019-7713-1

Elbarazi, I., Loney, T., Yousef, S., \& Elias, A. (2017). Prevalence of and Factors Associated with Burnout among Health Care Professionals in Arab Countries: A Systematic Review. BMC Health Services Research, 17, 491. https://doi.org/10.1186/s12913-017-2319-8

Hameed, T. K., Masuadi, E., Al Asmary, N. A., Al-Anzi, F. G., \& Al Dubayee, M. S. (2018). A Study of Resident Duty Hours and Burnout in a Sample of Saudi Residents. BMC Medical Education, 18, 180. https://doi.org/10.1186/s12909-018-1300-5

Le Gall, J. R., Azoulay, É., Embriaco, N., Poncet, M. C., \& Pochard, F. (2011). Épuisement professionnel en réanimation. Bulletin de l'Académie Nationale de Médecine, 195, 389-398. https://doi.org/10.1016/S0001-4079(19)32097-7

Lee, S.-J., Jung, S. I., Kim, M.-G., Park, E., Kim, A.-R., Kim, C. H., Jung, T.-D. et al. (2021). The Influencing Factors of Gender Differences on Mental Burdens in Young Physiotherapists and Occupational Therapist. International Journal of Environmental Research and Public Health, 18, 2858. https://doi.org/10.3390/ijerph18062858

Lin, R., Lin, Y., Hsia, Y., \& Kuo, C. (2021). Long Working Hours and Burnout in Health Care Workers: Non-Linear Dose-Response Relationship and the Effect Mediated by Sleeping Hours-A Cross-Sectional Study. Journal of Occupational Health, 63, e12228. https://doi.org/10.1002/1348-9585.12228

Monaghan, T., Dinour, L., Liou, D., \& Shefchik, M. (2017). Factors Influencing the Eating Practices of Hospital Nurses during Their Shifts. Workplace Health \& Safety, 66, 331-342. https://doi.org/10.1177/2165079917737557

Shahriari, M., Shamali, M., \& Yazdannik, A. (2014). The Relationship between Fixed and Rotating Shifts with Job Burnout in Nurses Working in Critical Care Areas. Iranian Journal of Nursing and Midwifery Research, 19, 360-365. https://doi.org/10.17795/nmsjournal27766

Williamson, K., Lank, P. M., Cheema, N., Hartman, N., \& Lovell, E. O. (2018). Comparing the Maslach Burnout Inventory to Other Well-Being Instruments in Emergency Medicine Residents. Journal of Graduate Medical Education, 10, 532-536. https://doi.org/10.4300/JGME-D-18-00155.1 
Wisetborisut, A., Angkurawaranon, C., Jiraporncharoen, W., Uaphanthasath, R., \& Wiwatanadate, P. (2014). Shift Work and Burnout among Health Care Workers. Occupational Medicine, 64, 279-286. https://doi.org/10.1093/occmed/kqu009 